\title{
SEQUÊNCIA DIDÁTICA SOBRE MICRORGANISMOS DA ÁGUA PARA O ENSINO DE CIÊNCIAS NOS ANOS INICIAIS DO ENSINO FUNDAMENTAL
}

\author{
DIDACTIC SEQUENCE ON WATER MICROORGANISMS FOR SCIENCE \\ TEACHING IN THE INITIAL YEARS OF ELEMENTARY EDUCATION
}

DOI: http://dx.doi.org/10.23926/RPD.2526-2149.2018.v3.n2.p557-574.id242

\section{Maira dos Santos \\ Silveira \\ Graduanda em Ciências \\ Biológicas (UFSM). \\ mairasantossilveira@gmail.c}

$\underline{\text { om }}$

\section{Ariadne de Freitas \\ Leonardi \\ Graduanda em Ciências \\ Biológicas (UFSM). \\ ariadneleonardi@hotmail.co \\ $\underline{\mathrm{m}}$}

\section{Geovane Bernardi \\ Graduando em Ciências \\ Biológicas (UFSM). \\ geovanebernardii@gmail.co $\mathrm{m}$}

\section{Sabrina Antunes Ferreira \\ Graduanda em Ciências \\ Biológicas (UFSM). \\ sabrinaantunesferreira@hot \\ mail.com}

\author{
Andréa Inês \\ Goldschmidt \\ Doutora em Educação em \\ Ciências (UFSM). \\ Professora na Universidade \\ Federal de Santa Maria \\ (UFSM) \\ andreainesgold@gmail.com
}

\begin{abstract}
Resumo: A pesquisa objetivou construir e validar uma Sequência Didática (SD) sobre microrganismos da água, tendo sido desenvolvida com um grupo de oitenta e nove alunos dos anos iniciais do Ensino Fundamental, de uma escola pública da rede estadual do Rio Grande do Sul, localizada em Palmeira das Missões. Foram realizadas diferentes atividades, como: modelagem de microrganismos com massinha de modelar; observação de amostras de água ao microscópio; e, uma atividade lúdica com as gotinhas de água Gotilde e Pingote. Para a avaliação foi realizado a construção de um texto pelos alunos, seguida da análise de conteúdo. Os resultados evidenciaram boa aceitação da $\mathrm{SD}$, tendo sido citadas todas as atividades realizadas, com percentuais mais elevados para a observação ao microscópio e para a confecção de modelo tridimensional com massa de modelar. $\mathrm{O}$ uso das estratégias contribuiu para melhor aprendizagem dos alunos, auxiliando no reconhecimento de que os microrganismos podem estar em todos os ambientes, que existem diferentes formas e tamanhos; e que estes seres microscópicos não são somente maléficos. Desta forma, as estratégias de ensino se mostraram pertinentes, representando uma alternativa potencialmente significativa na aprendizagem sobre microrganismos nos anos iniciais.
\end{abstract}

Palavras-chave: Primeiros anos. Aulas práticas. Aprendizagem.

\begin{abstract}
The research aimed to construct and validate a Didactic Sequence on water microorganisms. It was developed with a group of eighty - nine students from the initial years of Elementary School, from a public school of the state network of Rio Grande do Sul, located in city Palmeira das Missões. Different activities were carried out, such as: modeling of microorganisms with modeling clay; observation of water samples under a microscope; and, a playful activity with the droplets of water Gotilde and Pingote. For the evaluation was made the construction of a text by the students, followed by content analysis. The results showed a good acceptance of DS, and all the activities performed were mentioned, with higher percentages for observation under the microscope and for the making of a three-dimensional model with modeling mass. The use of the strategies contributed to the better learning of the students, aiding in the recognition that the microorganisms can be in all the environments, that there are different forms and sizes; and that these microscopic beings are not only maleficent. In this way, teaching strategies were relevant, representing a potentially significant alternative in learning about microorganisms in the early years.
\end{abstract}

Keywords: First years. Practical classes. Learning. 
Revista Prática Docente (RPD)

ISSN: 2526-2149 


\section{INTRODUÇÃO}

O ensino de Microbiologia, onde os microrganismos são personagens fundamentais, possui uma abstração muito forte e dependendo de como o professor desenvolver os conteúdos, esses conhecimentos raramente ganharão significado para o discente, que passará apenas a memorizá-lo sem que os tenham aprendido de fato. Desta forma, tem-se evidenciado um aprendizado deficiente por parte dos alunos, muitas vezes associado à construção de um conhecimento equivocado, baseado na utilização de metodologias ineficazes de ensino. Welker (2007) afirma que muitas vezes, essa deficiência na aprendizagem está vinculada a forma pouco atrativa do ensino para os alunos, fazendo com que eles percebam o conhecimento como meramente teórico, distante da realidade, gerando pouco interesse em ser estudado.

Krasilchik (2011) afirma que o aprendizado dos alunos sobre o ensino de Biologia tem sido precário, não sendo capaz de ultrapassar os mecanismos de memorização de informações que são muitas vezes irrelevantes e não relacionadas à realidade do aluno. Os alunos se veem obrigados a decorar conceitos e nomes que, na maioria das vezes, não fazem sequer sentido (WELKER, 2007). Os conteúdos são apenas memorizados por um período limitado, apenas visando à avaliação e, geralmente, são esquecidos logo em seguida, o que evidencia a não ocorrência de um aprendizado concreto (PELIZZARI et al., 2002; POSSOBOM, OKADA e DINIZ, 2003), tampouco a transformação daquela informação em conhecimento.

Leite e Esteves (2005) apontam o papel do professor neste processo, sinalizando a importância de se trabalhar estratégias de ensino capazes de facilitar a aprendizagem de tais conceitos e inter-relações pelos seus alunos. O lúdico pode ser uma alternativa a ser utilizada em sala de aula, como promotor da aprendizagem nas práticas escolares, possibilitando a aproximação dos alunos ao conhecimento científico.

Santos (1997), discorre que o lúdico tem sua origem na palavra latina "ludus" que quer dizer "jogos" e "brincar", o que oportuniza a aprendizagem do indivíduo.

Chaguri (2006) afirma que o lúdico é caracterizado pelo prazer e esforço espontâneo, capaz de envolver o indivíduo de forma intensa e total, criando um clima de entusiasmo. Este envolvimento emocional é que transforma o lúdico em uma atividade motivadora, capaz de gerar um estado de vibração e euforia. Sobre isto, Rizzo Pinto (1997) sinaliza que não há aprendizagem sem atividade intelectual e sem prazer; ou seja, a motivação através da ludicidade é uma boa estratégia para que a aprendizagem ocorra de forma efetiva.

Borges e Neves (2005) afirmam que através da ludicidade o aluno explora muito mais sua criatividade, melhora sua conduta no processo de ensino-aprendizagem e sua autoestima. 
O que diferencia uma situação lúdica educativa de outra de caráter apenas lúdico é o fato da primeira ter uma intenção explícita de provocar aprendizagem significativa, estimular a construção de novos conhecimentos e, principalmente, despertar o desenvolvimento de uma habilidade operatória que possibilite a compreensão e a intervenção do indivíduo nos fenômenos sociais e culturais e que o ajude a construir novas conexões mentais (NUNES, 2003).

Diversos pesquisadores debatem sobre a importância do ensino de Ciências nos anos iniciais do Ensino Fundamental e evidenciam que os alunos dessas turmas podem ir além da “observação e da descrição dos fenômenos, habilidades básicas comumente almejadas e trabalhadas pelos professores" (CARVALHO et al, 2007, p. 21). Entretanto, este ainda tem sido trabalhado de forma precária, tonando-se complexo e abstrato, sem significado para a vida dos alunos.

Neste sentido, o ensino de Ciências, nos anos iniciais, precisa ser valorizado e as metodologias utilizadas pelos professores devem ser repensadas com o intento de possibilitar uma atenção especial em relação à faixa etária desses alunos.

Uma das áreas que merece atenção, é o ensino em Microbiologia, pois este conhecimento assume extrema importância para a construção de cidadãos mais conscientes, uma vez que essa área, está diretamente relacionada à saúde, à higiene pessoal e ao funcionamento do meio ambiente (CASSANTI et al., 2007). Sem a existência de estratégias de ensino-aprendizagem eficientes, o mundo dos microrganismos se torna extremamente abstrato para os alunos (CASSANTI et al., 2007).

A Microbiologia é a ciência que estuda o papel dos microrganismos no mundo, principalmente em relação à sociedade humana, ao corpo humano e ao meio ambiente. Assim, ela oferta aos alunos uma visão ampla sobre os seres microscópicos, bem como de sua importância para a saúde humana, manutenção do equilíbrio ecológico e diversas aplicações e benefícios tanto individuais quanto coletivos (MADIGAN, MARTINKO e PARKER, 2004; PELCZAR, CHAN e KRIEG, 1997). Portanto, compreender a Microbiologia e desenvolver competências relacionadas a esta, é de grande importância para propiciar uma qualidade de vida àquele que aprende (CARNEIRO, MELO e SANTOS, 2012).

Albuquerque, Braga e Gomes (2012) discutem sobre as dificuldades no ensino de Microbiologia e apontam que prevalece entre os alunos, uma ideia reducionista sobre esses seres vivos, que não favorece o ensino, pois impede de imaginar a variedade de microrganismos presentes em nosso planeta e que apesar de trazerem alguns malefícios, a existência dessas 
formas de vida minúsculas é vital para a vida de diversos outros organismos. Além disso, conhecer os microrganismos oferece aos alunos uma visão ampla de sua importância para a saúde humana, manutenção do equilíbrio ecológico e diversas aplicações comerciais. Ao relacionar esses pequenos seres ao cotidiano, o aluno passa a estabelecer uma relação entre a teoria e o que ocorre na realidade, possibilitando eficácia na aprendizagem.

Pinho (2000) discute sobre a importância de uma transposição didática adequada, de modo que a proposta pedagógica seja significativa e favoreça a aprendizagem. Nesse contexto, explorar uma Sequência Didática (SD) para o ensino de Microbiologia nos anos iniciais pode contribuir para a atuação de docentes ao trabalhar com os educandos aspectos dessa temática. Ao se aliar os aspectos lúdicos com os cognitivos, pode-se propor ferramentas metodológicas para a aprendizagem de conceitos abstratos e complexos que favorecem a motivação interna, o raciocínio, a argumentação, a interação entre os alunos e entre alunos e professores.

Guimarães e Giordan (2012) discorrem que a SD é um conjunto de atividades articuladas e organizadas de forma sistemática, em torno de uma problematização central, planejadas para ensinar um conteúdo, organizadas de acordo com os objetivos que o professor quer alcançar para a aprendizagem de seus alunos e para tornar mais eficiente o processo de aprendizado.

Diante do exposto, o objetivo desta pesquisa foi propor e avaliar uma SD para desenvolver o conteúdo sobre microrganismos da água com alunos de anos iniciais do Ensino Fundamental e que esta proposta contribuísse para a superação do modelo tradicional de ensino, pautado geralmente na transmissão de conteúdo, despertando maior interesse nos discentes.

\section{Metodologia}

Trata-se de um estudo envolvendo o ensino e a aprendizagem, realizado com estudantes do $2^{\circ}, 3^{\circ}, 4^{\circ}$ e $5^{\circ}$ anos do Ensino Fundamental (primeiro ciclo), na faixa etária entre sete a doze anos, de uma escola pública no município de Palmeira das Missões, RS. A amostra constou de duas turmas de $2^{\circ}$ ano, uma turma de $3^{\circ}$ ano, uma turma de $4^{\circ}$ ano e uma turma de $5^{\circ}$ ano. Os alunos foram convidados a participarem da pesquisa, assinando juntamente aos familiares, o Termo de Consentimento Livre e Esclarecido. As atividades que compõem a SD foram desenvolvidas pelo grupo de pesquisadores, autores deste artigo e que se encontram em formação inicial docente em Ciências Biológicas. A pesquisa contou ainda com a participação, como observadores, de cinco professoras, responsáveis pelas turmas na escola. 
A pesquisa empírica consistiu na elaboração, desenvolvimento e avaliação da SD sobre microrganismos da água. A validação da SD foi desenvolvida dentro de uma abordagem de pesquisa quanti-qualitativa, constituindo o corpus de análise, oitenta e nove (89) questionários individuais, contendo uma única questão aberta, "O que mais gostou e/ou o que aprendeu com as atividades? "O questionário foi respondido ao término da $\mathrm{SD}$, tendo sido recolhido e analisado a partir da análise de conteúdo, proposto por Bardin (2011).

\subsection{DeSEnVolvimento da SequênCIA DidÁtica "Microrganismos Da ÁGUA"}

A SD proposta foi desenvolvida a partir de três atividades distintas, tendo sido aplicada em cada uma das turmas participantes, de forma separada e levando-se em consideração o desenvolvimento cognitivo dos estudantes nas distintas faixas etárias.

Inicialmente foi explicado aos alunos a dinâmica das atividades a serem desenvolvidas e os alunos foram agrupados em quatro grupos, mantendo uma distribuição uniforme, de acordo com o número de participantes em cada turma dos anos inicias.

Para a atividade inicial foi proposta a construção cognitiva de microrganismos com a massinha de modelar (doze kits de massinha de modelar com doze cores), no intuito de atentar às concepções existentes sobre esses seres vivos e sobre a morfologia dos microrganismos (Atividade 1).

Em continuidade à SD, foi mostrado aos alunos cinco tubos de ensaio contendo diferentes amostras de água (Atividade 2). Em dois destes, havia água transparente, em um terceiro, amostra de água barrenta, outro contendo água um pouco turva e um último, com amostra de água esverdeada.

Simultaneamente à visualização destes vidros laboratoriais com amostras de águas, foram apresentados aos alunos dois personagens confeccionados em EVA (do inglês, Ethylene Vinyl Acetate). Esses se referiam à imagem de duas gotinhas de água: Gotilde e Pingote, representando a água limpa e água suja respectivamente. Estas figuras foram fixadas ao quadro e foi informado aos alunos que a Gotilde era uma gotinha de água limpa, que adorava as frutas, verduras e legumes. Gostava muito das mãos limpas e da higiene, mas que detestava desperdício de água. Já, a gotinha Pingote representava a água suja, que adorava a Gotilde. Porém, para conseguir frequentar os mesmos lugares que a Gotilde, ela precisava passar por um rigoroso tratamento.

Após apresentar as "gotinhas", cada grupo de alunos recebeu de três a quatro imagens, também confeccionadas em EVA e que deveriam ser observadas pelos grupos, para posterior 
classificação em uma das gotinhas. As imagens distribuídas nos grupos foram: Grupo 1) máquina de lavar roupa, amostra de água em microscópio e água da torneira; Grupo 2) vaso sanitário, chuveiro e nuvem com água da chuva; Grupo 3) piscina, rio e frutas; e, Grupo 4) mãos lavadas, chocolate, verme e protozoário (microrganismos). Ainda, foram distribuídos entre os alunos, os vidrinhos com as amostras de água. Os alunos tiveram um tempo de dez minutos para discutirem sobre as figuras e amostras de água recebidas e decidirem se alocariam as mesmas junto à Gotilde ou à Pingote. Oralmente, cada grupo apresentou suas decisões, justificando-as. As figuras foram fixadas ao quadro, juntamente às gotinhas. Os vidrinhos com água mostrados anteriormente também foram alocados junto à gotinha Gotilde ou à gotinha Pingote, de acordo com as decisões tomadas pelos alunos. Uma a uma, as imagens foram apresentadas e questionadas em relação à classificação realizada por eles.

A última atividade (Atividade 3) consistiu na preparação de lâminas de vidro de amostras das águas da atividade anterior, para observação ao microscópio óptico. Foram levados até a escola, quatro microscópios. Primeiramente as amostras foram visualizadas a olho nu para que os alunos pudessem verificar a cor, o odor e os aspectos em geral. Os alunos foram questionados: "Será que existem seres vivos em alguma das amostras? Que seres seriam esses? E se existissem, é possível observá-los com uma lupa?" Foi fornecido aos alunos lupas para investigarem inicialmente. Percebendo não ser possível, os alunos tiveram a oportunidade de observarem ao microscópio óptico.

\section{Resultados e Discussão}

Em relação à construção de modelos tridimensionais de microrganismos a partir de massinha de modelar (Figura 1), pode-se constatar que as formas criadas pelos participantes incluem três representações distintas: (I) imaginários de "monstrinhos" (Figura 1A); (II) representantes de insetos e outros invertebrados (Figura 1B e C); e, imagens morfológicas bacterianas existentes - cocos e/ou bacilos (Figura 1D), já incorporadas às concepções desses alunos. Estas representações foram distribuídas uniformemente entre os alunos, independentes do nível de ensino. Os resultados mostram que nos anos iniciais ainda não há, entre os discentes, clareza a respeito das possíveis morfologias para microrganismos e que o fato de se tratarem de organismos muito pequenos faz com que muitos alunos os associem a formas reconhecidas como insetos, minhocas e caracóis, sem distinção entre os anos de ensino.

Nessa atividade, foi possível evidenciar as concepções de microrganismos com feições malvadas, provavelmente como reflexo da ideia que se tem de bactérias como organismos 
nocivos e perigosos. Lopes et al. (2015), sinalizam que essas representações midiáticas podem gerar concepções alternativas para os alunos, às quais devem ser problematizadas pelo educador em sala de aula. Também foi comum a representação como insetos e/ou outros invertebrados. Costa Neto e Carvalho (2000) apresentam que o senso comum julga os insetos como sendo organismos nojentos, perigosos, repugnantes e inúteis para a sociedade. Dessa forma, por vezes, as crianças os consideram micróbios.

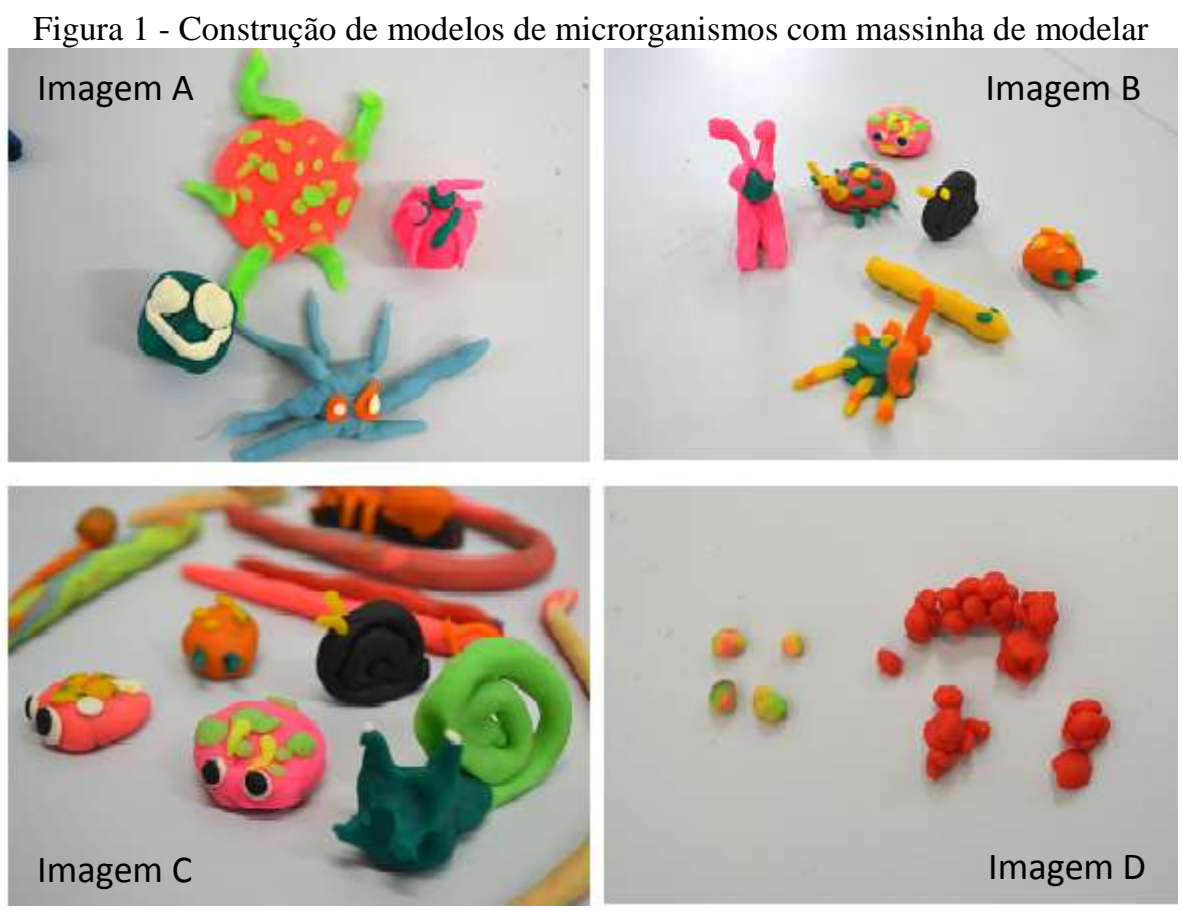

Fonte: Elaborado pelos autores

Os resultados da atividade relacionada à estratégia das gotinhas Gotilde e Pingote, tornaram possível uma discussão a partir da classificação inicial que os discentes realizaram, a partir das imagens fornecidas a eles. Esta classificação inicial, não teve interferência dos professores pesquisadores. Observou-se que alguns elementos tiveram maior facilidade para a classificação, enquanto que outros provocaram dúvidas nos alunos. Desta forma, a medida que foi discutida cada uma das imagens e ouvido os argumentos fornecidos pelos alunos para a classificação realizada, os discentes eram questionados sobre quais as diferenças entre a água potável e não potável; entre águas poluídas e/ou contaminadas; e ainda, se uma água aparentemente limpa é necessariamente potável?

Pelczar, Chan e Krieg (1997) afirmam que água contaminada é aquela que contém micróbios vivos, sejam bactérias, vermes, protozoários ou vírus, com capacidade de causar doenças e a morte. Já, a água poluída é aquela que tem cheiro forte, cor escura, com características naturais alteradas; ou seja, que deixou de ser pura e saudável para o homem. 
Porém, tal condição não implica necessariamente em estar contaminada com microrganismos patógenos. Ainda, segundo os autores, uma água potável é aquela que pode ser consumida sem riscos à saúde, seguindo padrões físicos, químicos e biológicos, estabelecidos pelas leis de órgãos nacional e internacional que controlam esta qualidade.

O objetivo dos questionamentos era que esta discussão inicial alertasse aos alunos que o fato de uma água estar transparente; ou parecer limpa, não garante a esta a potabilidade, sendo discutido com os participantes sobre a contaminação invisível e os riscos oferecidos pela presença de microrganismos ou outras substâncias perigosas, que não são detectados a olho nu.

Em relação às imagens oferecidas aos alunos, a classificação inicial, agrupou para a gotinha Pingote, além das amostras de água com distintas colorações nos tubos de ensaio, as imagens da amostra de água em microscópio, a água da piscina, o rio; e, os microrganismos (representados pelas imagens de verme e protozoário). Já para a Gotilde, além das amostras de água transparentes, aglutinou as imagens da água da máquina de lavar roupa, a água da torneira, o chuveiro, as frutas, as mãos lavadas, e o chocolate (Figura 2). Os alunos apresentaram, dificuldades para classificarem nos grupos, a nuvem com água da chuva e o vaso sanitário. Os resultados das classificações realizadas pelos alunos mostraram que para eles, quase em unanimidade, o fato de a água estar transparente, seria sinônimo de se tratar de uma água potável e sem prejuízos para a saúde, mostrando que os respondentes ainda desconhecem os riscos, em função de se tratar de um mundo microscópico.

Levando em consideração as classificações e os questionamentos dos alunos, julgou-se importante explicar que para o consumo humano, a água além de estar cristalina, deve estar potável. Desta forma, os alunos compreenderam que não basta ser Gotilde, é necessário ser uma Super Gotilde, e que esta representaria a água potável, e não apenas aparentemente limpa. Foi discutido com os alunos que nessa definição, se enquadrava a água da torneira, que passou por um tratamento prévio e que não pode sofrer contaminações nos canos. Esta deve ser potável, para a limpeza das frutas, verduras, legumes e preparação de alimentos, assim como para a higiene das mãos. Desta forma, as imagens que haviam sido colocadas para a imagem da gotinha Gotilde, foram realocadas para a Super Gotilde (para esta usou-se uma segunda imagem, semelhante a primeira, mas que possuía uma estrelinha na extremidade anterior da gota).

Ainda, foi classificada neste grupo, a água presente nos alimentos ou para prepará-los nas indústrias (como por exemplo, as imagens das frutas e do chocolate). Deste modo, teve-se uma reclassificação do que os alunos fizeram inicialmente, separando a Gotilde, em dois 
subgrupos (Super Gotilde: água potável; e, Gotilde: água limpa, sem riscos à saúde, mas que não pode ser consumida in natura). Esta última poderia ser a situação da água do chuveiro, da água para descargas e da água para ser usada na máquina de lavar roupas. Esta água deve estar limpa, mas não necessariamente potável; ou seja, não necessitaria de um tratamento químico severo como a água para ser consumida. Através desses exemplos, buscou-se sensibilizar os discentes sobre o quanto é um desperdício utilizar água potável para descarga, assim como a água do chuveiro, podendo-se optar pelo reaproveitamento de água, como coleta de água da chuva.

Ainda foi questionado sobre a água da piscina. A água da piscina visivelmente foi considerada limpa pelos alunos; porém, discutiu-se que esta possui uma grande quantidade de cloro dissolvido nela, o que a inviabiliza para consumir. Assim, os alunos perceberam que não poderia ser considerada uma Super Gotilde (Figura 2).

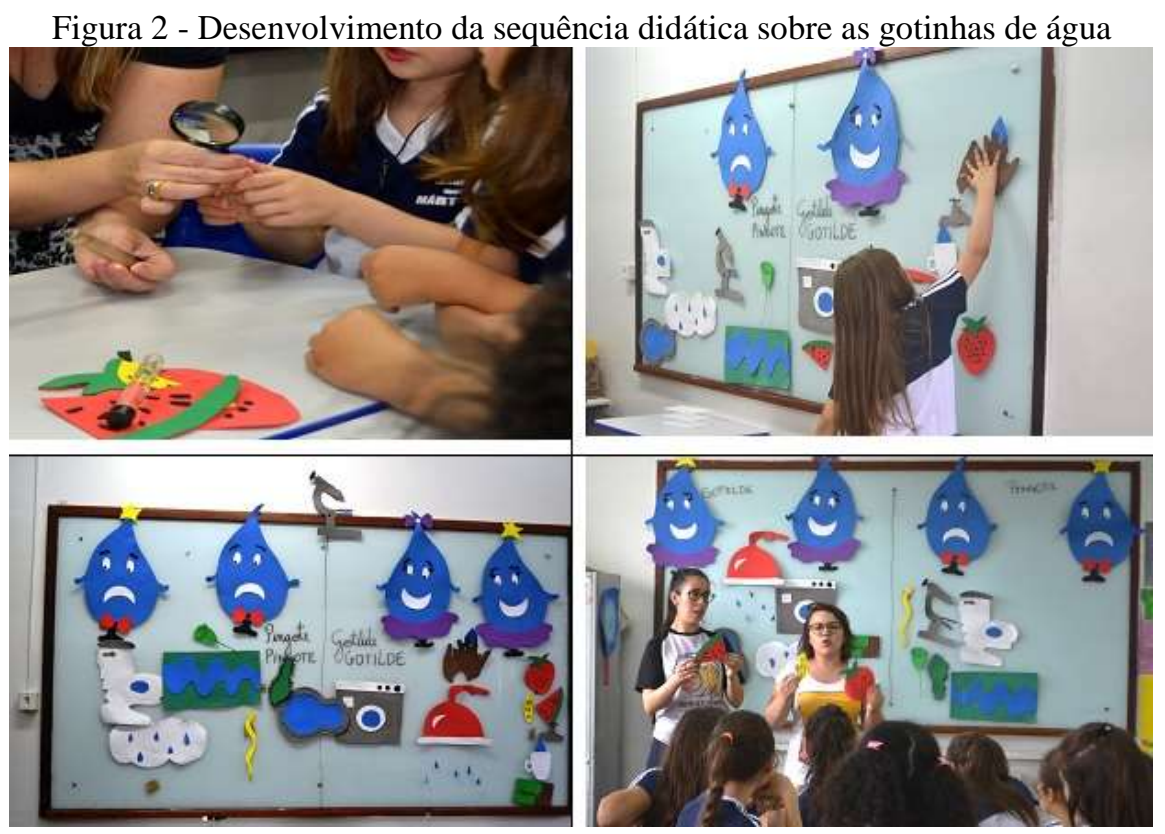

Fonte: Elaborado pelos autores

Foi explicado aos discentes, que há algumas águas, que mesmo na situação de Pingote, podem ser usadas para fins de recreação; como por exemplo, a água dos rios que é imprópria para consumo, porque há várias substâncias na água, desde folhas, terra, areia, pequenos animais, mostrando mudanças de coloração e turbidez. Mas também foi explicado que podem não estar presentes os microrganismos causadores de doenças, além de outras substâncias. Com isto, os participantes perceberam que nem sempre a Pingote oferece riscos à saúde e, embora essa água não possa ser tomada, apresenta benefícios para o ambiente, e pode ser utilizada para recreação, como por exemplo tomar banho no rio e brincar com a água. 
A água da chuva, inicialmente pode ser classificada como limpa; porém, ao discutir com os alunos, pode-se ressaltar que apesar de não serem enxergadas sujeiras, não significa que não existam. Dessa forma, também a água da chuva não pode ser usada para o consumo direto.

Durante a aplicação da SD, observou-se que as atividades foram conduzidas de modo a permitir aos alunos, a oportunidade de interação estudante-estudante e estudante-pesquisadores, possibilitando a exposição de suas ideias e elaboração de hipóteses, o que contribui para que se propiciasse um ambiente participativo.

A análise dos resultados provenientes dos oitenta e nove questionários, tornaram possível evidenciar 333 citações elaboradas pelos respondentes, organizadas em sete categorias que emergiram a posteriori e que são apresentadas na Tabela 1. Para fins de discussão os resultados foram calculados em percentuais e ultrapassam valor de $100 \%$, em virtude de cada participante poder apontar mais de uma categoria em suas construções textuais.

Tabela 1 - Representação das categorias de análise que emergiram na avaliação dos alunos de anos iniciais sobre a sequência didática desenvolvida

\begin{tabular}{l|c|c}
\hline Categorias de análise & Absoluto & $\%$ \\
\hline Reconhecimento das estratégias usadas & 128 & 38 \\
\hline Satisfação/Agradecimentos & 63 & 19 \\
\hline Características gerais dos microrganismos & 45 & 14 \\
\hline Saúde & 35 & 10 \\
\hline Reconhecimento de microrganismos benéficos e maléficos & 33 & 10 \\
\hline Importância do microscópio & 26 & 8 \\
\hline Erros conceituais & 03 & 1 \\
\hline Total Fonte: Elaborado pelos autores & 333 & 100 \\
\hline \multicolumn{2}{c}{}
\end{tabular}

Na tabela 1, a categoria que mais se destacou se refere ao uso de diferentes estratégias que compuseram a SD, tendo sido apontada por $38 \%$ dos alunos. Os resultados evidenciam que o uso de atividades diversificadas e lúdica agem como atrativo para a sala de aula, tendo sido citadas de forma significativa, nos textos produzidos em todos os níveis dos anos iniciais.

Castro e Goldschmidt (2016) discutem sobre a importância em desenvolver estratégias e alternativas que possam simplificar a linguagem usada em sala de aula, tentando torná-la mais simples e coerente. Ainda comentam que na tentativa de melhorar a dinâmica das aulas, a interação e a participação dos alunos, o professor pode recorrer a realização de aulas práticas.

Fracalanza, Amaral e Gouveia (1987) corroboram, afirmando que há um grande número de especialistas em ensino em Ciências que propõem a substituição de aulas meramente expositivas, baseadas nos livros didáticos, por atividades práticas. Segundo Berezuk e Inada (2010), a utilização de aulas práticas possibilita um aprendizado eficiente e estruturado. Kleinke (2003) considera que para haver aprendizagem significativa, deve haver significado. 
A Tabela 2 apresenta as subcategorias que emergiram para o reconhecimento das estratégias didáticas utilizadas na sequência didática desenvolvida com os alunos de anos iniciais do Ensino Fundamental, sobre microrganismos da água.

Tabela 2 - Representação das categorias de análise Reconhecimento das estratégias usadas e Satisfação, na avaliação dos alunos de anos iniciais sobre a sequência didática desenvolvida

\begin{tabular}{|c|c|c|c|}
\hline Categorias & Subcategorias de análise & Absoluto & $\%$ \\
\hline \multirow{6}{*}{$\begin{array}{l}\text { Reconhecimento } \\
\text { das estratégias } \\
\text { usadas }\end{array}$} & Citou a observação ao microscópio & 44 & 34 \\
\hline & Citou a construção de microrganismos com massinha & 25 & 19 \\
\hline & Citou/explicou a classificação da Gotilde e Pingote & 30 & 24 \\
\hline & Citou os tubos de ensaio com as diferentes águas e uso da lupa & 23 & 18 \\
\hline & Citou o trabalho em grupo & 05 & 4 \\
\hline & $\begin{array}{l}\text { Comentou sobre a importância em reaproveitar a água da } \\
\text { chuva }\end{array}$ & 01 & 1 \\
\hline \multicolumn{2}{|l|}{ Subtotal } & 128 & 38 \\
\hline $\begin{array}{l}\text { Satisfação/ } \\
\text { Agradecimentos }\end{array}$ & $\begin{array}{l}\text { Importante, interessante, legal, divertido, gostei do projeto, } \\
\text { adorei, ótima, produtiva, incrível }\end{array}$ & 63 & 100 \\
\hline \multicolumn{2}{|l|}{ Subtotal } & 63 & 19 \\
\hline
\end{tabular}

\section{Fonte: Elaborado pelos autores}

Em relação as estratégias usadas, 34\% dos alunos citaram a observação ao microscópio, o que é um percentual alto comparado as outras atividades realizadas. Provavelmente por ser algo diferente do que estão acostumados, e porque o uso deste equipamento permitiu aos alunos observarem o mundo microscópico, até então desconhecido.

Silva, Vieira e Oliveira (2009) afirmam que o uso do microscópio proporciona a dinamização das aulas, aproximando teoria e prática, o que torna visível aos discentes a percepção das estruturas microscópicas, visíveis até então somente através de fotos e imagens dos livros didáticos. Portanto, usar o microscópio pode contribuir para melhorar o processo de aprendizagem e o desempenho dos alunos, estimulando a participação e o interesse, pois permite a visualização do mundo microscópico, até então abstrato.

A estratégia usada para construção de modelo tridimensional de microrganismos também foi reconhecida de forma significativa pelos alunos (19\%). Matos et al. (2009) apontam que a ação de criar modelos permite ao aluno reproduzir o conhecimento sobre o objeto de estudo ao invés de apenas receber informações teóricas sobre o assunto em questão. Assim, uma dessas estratégias é a confecção e utilização de modelos tridimensionais a partir do uso de materiais de baixo custo, como a utilização de massa de modelar.

Observou-se também que muitos demonstraram alegria e empolgação na ação de confeccionar os microrganismos, o que corrobora com Beserra e Brito (2012), quando afirmam que a modelagem proporciona aos alunos o despertar de um lado lúdico e atrativo. Fortuna (2003) ressalta a importância das brincadeiras e atividades lúdicas na aprendizagem e no 
desenvolvimento humano. Assim, é importante destacar que o ato de brincar pode contribuir muito para a cognição de conteúdos complexos, como é o caso dos microrganismos.

Ainda foi muito significativo para os alunos, a classificação a respeito dos tipos de água. Os discentes não apenas citaram a classificação realizada, como teceram explicações a respeito. Mostraram-se surpresos com as discussões realizadas em sala de aula, sendo inclusive relatado pelos participantes em seus textos "fomos enganados"; e, "uma água que parece limpa, não quer dizer que é potável". Assim, pode-se evidenciar que as atividades que potencializam a investigação possibilitam a desmistificação de informações como a de que "uma água limpa e transparente é uma água potável".

Atividades lúdicas como a utilização das gotinhas Gotilde/Super Gotilde e Pingote/Super Pingote, foram lembradas por $24 \%$ dos alunos, podendo ser considerado um valioso recurso pedagógico, pois ultrapassa as barreiras do simples processo de transmissãorecepção de conhecimentos, possibilitando a socialização de opiniões num trabalho em grupo e a exploração de diversos conceitos de forma prazerosa. Além disso, pode-se destacar que desse universo, $9 \%$ explicaram toda a atividade realizada e as conclusões a que chegaram. Estes resultados indicam que a atividade, além de ser prazerosa, mostra-se também eficaz como estratégia facilitadora, para a compreensão do conteúdo.

As atividades tiveram boa aceitação, sendo citadas todas as modalidades realizadas, além de apontadas como "Importante, interessante, legal, divertida, ótima, produtiva e incrível" por $19 \%$ dos participantes.

Outra categoria que teve destaque está associada às características dos microrganismos. Esta totalizou $14 \%$ e também foi classificada quanto às subcategorias que emergiram a partir desta. Os resultados são encontrados na Tabela 3. 
Tabela 3 - Representação das categorias de análise Características gerais dos microrganismos e Importância do microscópio na avaliação dos alunos de anos iniciais sobre a sequência didática desenvolvida

\begin{tabular}{|c|c|c|c|}
\hline Categoria & Subcategorias de análise & Absoluto & $\%$ \\
\hline \multirow{7}{*}{$\begin{array}{l}\text { Características gerais dos } \\
\text { microrganismos }\end{array}$} & $\begin{array}{l}\text { Podem ser encontrados em todos os ambientes, até no } \\
\text { ar e roupas, no corpo, rios }\end{array}$ & 13 & 29 \\
\hline & São encontrados nas coisas limpas e nas sujas & 04 & 9 \\
\hline & $\begin{array}{l}\text { Alguns parecem flores; outros, plantas. Tem formas } \\
\text { diferentes, de bola, oval, e até de minhoca }\end{array}$ & 10 & 22 \\
\hline & São de tipos diferentes (fungos, vírus, bactéria) & 02 & 4 \\
\hline & Estudamos o formato/morfologia do microrganismo & 01 & 2 \\
\hline & $\begin{array}{l}\text { São muito pequenos/ invisíveis a olho nu/ tamanhos } \\
\text { diferentes no microscópio }\end{array}$ & 14 & 32 \\
\hline & Os microrganismos são muito sensíveis & 01 & 2 \\
\hline \multicolumn{2}{|l|}{ Subtotal } & 45 & 14 \\
\hline \multirow[t]{3}{*}{ Importância do microscópio } & $\begin{array}{l}\text { O microscópio permite ver os microrganismos que não } \\
\text { podemos enxergar }\end{array}$ & 17 & 65 \\
\hline & Muito importante este aparelho, pois aumenta as coisas & 6 & 23 \\
\hline & Importante pra diferenciar água limpa de suja & 3 & 12 \\
\hline \multicolumn{2}{|l|}{ Subtotal } & 26 & 8 \\
\hline
\end{tabular}

Fonte: Elaborado pelos autores

Os resultados mostram que os alunos reconheceram cinco características importantes que foram discutidas durante a atividade; sendo estas, morfologia, tipos microbianos (diversidade), tamanho, habitat (cosmopolitas, por serem encontrados em todos os locais); e, comportamento (irritabilidade em relação à luz no microscópio óptico).

Após a sequência didática $29 \%$ dos alunos reconheceram que os microrganismos podem ser encontrados em todos os ambientes, até mesmo no ar, nas roupas, no nosso corpo e nos rios. Tanto em lugares sujos como em limpos, sendo isto citado por $9 \%$ dos alunos, desmistificando as concepções errôneas sobre esses seres microscópicos estarem somente associados à sujeira.

Franco et al. (2012) e Leporo (2009), relatam que as crianças relacionam a existência dos microrganismos a quase todos os ambientes, até em seu corpo; porém, a maioria delas associa os seres microscópicos à doença e à sujeira. Portanto, desenvolver estas ideias com os alunos é importante, para desmistificar esta visão reducionista que tem dificultado a compreensão dos alunos sobre a grande variedade de microrganismos no nosso planeta; e, que embora alguns tragam malefícios, a grande maioria é benéfica.

Pessoa et al. (2012), afirmam que a Microbiologia por ser relativamente complexa e por tratar de organismos invisíveis a olho nu, a disciplina costuma ser trabalhada nas escolas de forma teórica e com pouca experimentação, uma vez que a falta de equipamentos e materiais no ensino público inviabiliza a realização de aulas práticas de Ciências, dificultando o aprendizado e sua aplicação. Desta forma, oportunizar aos alunos a visualização do mundo microscópico é importante para facilitar a compreensão. 
Os participantes além de reconhecerem a importância do aparelho microscópio para a visualização dos microrganismos (8\%), puderam perceber as formas distintas, não reconhecidas por eles inicialmente, como os vermes e os protozoários.

A Tabela 4 elucida os resultados encontrados para as categorias Saúde e Reconhecimento de microrganismos benéficos e maléficos, também bem representativa para os participantes.

Tabela 4. Representação das categorias de análise Saúde e Reconhecimento de microrganismos benéficos e maléficos, na avaliação dos alunos de anos iniciais sobre a sequência didática desenvolvida

\begin{tabular}{|c|c|c|c|}
\hline Categoria & Subcategorias de análise & Absoluto & $\%$ \\
\hline \multirow{10}{*}{ Saúde } & $\begin{array}{l}\text { Antes de bebermos alguma coisa temos que perguntar de } \\
\text { onde aquilo veio }\end{array}$ & 07 & 20 \\
\hline & Devemos lavar sempre as mãos & 07 & 20 \\
\hline & Devemos lavar o que formos comer & 04 & 11 \\
\hline & $\begin{array}{l}\text { Temos que lavar as mãos para evitar doenças e } \\
\text { contaminações }\end{array}$ & 01 & 3 \\
\hline & $\begin{array}{l}\text { Temos que cuidar do nosso corpo para não ficarmos } \\
\text { doentes }\end{array}$ & 02 & 6 \\
\hline & $\begin{array}{l}\text { A água limpa é mais saudável e a suja prejudica nossa } \\
\text { saúde, pois tem microrganismos. Assim, precisa de } \\
\text { filtragem }\end{array}$ & 04 & 11 \\
\hline & A água limpa não pode ter microrganismos & 03 & 9 \\
\hline & Não devemos entrar em rios com lixo e sujeira & 03 & 9 \\
\hline & Aprendi sobre o que é limpo e o que não é & 03 & 9 \\
\hline & É importante escovar os dentes e puxar a descarga & 01 & 3 \\
\hline \multicolumn{2}{|l|}{ Subtotal } & 35 & 11 \\
\hline \multirow{3}{*}{$\begin{array}{l}\text { Reconhecimento de } \\
\text { microrganismos } \\
\text { benéficos e maléficos }\end{array}$} & $\begin{array}{l}\text { Aprendi que existem microrganismos do bem e do mal, } \\
\text { "pode até fazer queijo e iogurte" }\end{array}$ & 21 & 64 \\
\hline & $\begin{array}{l}\text { As bactérias do mal podem prejudicar a saúde, as outras } \\
\text { não }\end{array}$ & 03 & 9 \\
\hline & $\begin{array}{l}\text { Existem microrganismos que ajudam a limpar ás águas dos } \\
\text { rios, se alimentam das sujeiras. }\end{array}$ & 09 & 27 \\
\hline \multicolumn{2}{|l|}{ Subtotal } & 33 & 10 \\
\hline
\end{tabular}

Fonte: Elaborado pelos autores

Com a SD desenvolvida os alunos perceberam a importância de uma boa higiene para a manutenção da saúde, ao citarem que devem lavar as mãos sempre (20\%), e que com a lavagem das mãos são evitadas doenças e contaminações (3\%). Igualmente foi citado outros hábitos importantes de higiene pessoal e com o próprio meio.

Os resultados mostram o quão impactante foi o sentimento acerca da questão de se sentirem "enganados" com os tubos de água transparente; tanto, que 20\% dos participantes citou que "antes de bebermos algo devemos saber de onde aquilo veio, pois, a água pode parecer limpa, mas não está". Sobre isso, Castro et al. (2003) discutem que as doenças de veiculação hídrica são caracterizadas principalmente pela ingestão de água contaminada por 
microrganismos patogênicos de origem entérica, animal ou humana, transmitidos basicamente pela rota fecal-oral.

Com relação ao reconhecimento dos microrganismos, $10 \%$ dos alunos destacou-os como benéficos e maléficos. É interessante destacar que 64\% dos participantes afirmaram que aprenderam que os microrganismos estão presentes inclusive nos alimentos, citando o processo de preparação de queijos e iogurtes.

Barbosa e Oliveira (2015) enfatizam o papel da escola nessa mudança de concepção. Para eles, o receio que existe com relação a esses seres microscópicos ocorre geralmente pela divulgação dos impactos negativos que eles causam, como por exemplo, as doenças em seres humanos, deixando de lado a importância como suporte à vida humana que eles desempenham e ao meio ambiente. Assim, é importante que os alunos compreendam que esses seres microscópicos estão em toda parte e que são componentes da nossa microbiota, auxiliando inclusive, na agricultura, nas indústrias, nos laboratórios e na produção de alimentos. Os microrganismos estão relacionados com a vida humana de diversas formas, tanto provocando doenças e complicações, mas também apresentando inúmeras associações benéficas. (ALBUQUERQUE, BRAGA e GOMES, 2012).

Além disso, outra importância destacada por $27 \%$ dos alunos é de que os microrganismos estão presentes nos rios, atuando como purificadores da água através de processos naturais de reciclagem da matéria orgânica. Os discentes reconheceram a importância destes seres vivos para o meio ambiente, "limpando a natureza". Os alunos citaram os mesmos como responsáveis por processos de decomposição e para o crescimento de plantas.

Por fim, a última categoria a emergir na análise dos resultados foram os erros conceituais apontados pelos alunos na construção dos textos. Estes foram mínimos, totalizando 0,90\%. Foram erros não significativos, e inclusive ortográficos, pela dificuldade de algumas palavras e expressões. Essas foram, "microrganismo é parecido com uma bactéria" em uma citação; "microrganismos transmitem muitos germes" em outra citação e estetoscópio ao invés de microscópio, em cinco citações das 333 citações apontadas pelos alunos nos 89 textos produzidos.

\section{CONSIDERAÇÕES FinaIS}

A sequência didática proposta para o ensino em Ciências nos anos iniciais, com a temática microrganismos da água, atendeu aos objetivos propostos, contribuindo para despertar o interesse, envolver os alunos nas investigações, resolver problemas e serem capazes de 
compreender conceitos básicos. As atividades foram significativas, prazerosas e oportunizaram aos alunos expressarem suas opiniões e seus conhecimentos, socializando-se e interagindo com os professores e com seus colegas.

A organização do trabalho pedagógico a partir das sequências didáticas facilita o dia a dia em sala de aula, dando uma maior segurança para o professor proceder, principalmente quando o assunto é Ciências nos anos iniciais e a ênfase normalmente é dada a alfabetização e ao ensino de Matemática. Contribui para uma aprendizagem mais significativa, à medida que o professor deixa de simplesmente transmitir conhecimento para assumir o papel de criador de situações estimulantes, e consequentemente, os alunos participam ativamente no processo. Quando estas associam a ludicidade, a linguagem utilizada em sala de aula assume um caráter facilitador e associa aprender ao prazer.

Espera-se que este artigo contribua como um material importante para auxiliar o desenvolvimento do tema em outras turmas, pois todas as atividades propostas têm potencial para utilização nas escolas, em função da acessibilidade, baixo custo dos recursos utilizados e possibilidade de adequação das atividades em diferentes contextos.

\section{REFERÊNCIAS}

ALBUQUERQUE, G. G.; BRAGA, R. P. S. e GOMES, V. Conhecimento dos alunos sobre microrganismos e seu uso no cotidiano. Revista de Educação, Ciências e Matemática, Rio de Janeiro, v. 2, n. 1, p. 58-64, 2012.

BARBOSA, F. G. e OLIVEIRA, N. C. Estratégias para o Ensino de Microbiologia: uma Experiência com Alunos do Ensino Fundamental em uma Escola de Anápolis-GO. Cient., Ciênc. Human. Educ., UNOPAR, Londrina, v. 16, n. 1, p. 5-13, Jan. 2015.

BARDIN, L. Análise de conteúdo. São Paulo: Edições 70, 2011.

BEREZUK, P.A e INADA, P. Avaliação dos laboratórios de Ciências e biologia das escolas públicas e particulares de Maringá, Estado do Paraná. Acta Scientiarum. Human and Social Sciences. Maringá, v. 32, n. 2, p. 207-215, 2010

BESERRA, J. G. e BRITO C. H. Modelagem didática tridimensional de artrópodes, como método para o ensino de Ciências e Biologia. Revista brasileira de ensino de Ciência e tecnologia. Bananeiras, Paraíba, v. 5, n. 3, p. 70-88, 2012.

CARNEIRO, M. R. P.; MELO C. R. T. M. S. C. e SANTOS, D. R. Percepção dos alunos do Ensino Fundamental da rede pública de Aracaju sobre a relação da Microbiologia no cotidiano. Scientia plena, 8, 1-4, 2012.

CARVALHO, A. M. P. et al. Ciências no Ensino Fundamental: o conhecimento físico. São Paulo: Scipione, 2007. 
CASSANTI, A. C et al. Microbiologia democrática: estratégias de ensino-aprendizagem e formação de professores. Colégio Dante Alighieri. São Paulo: 2007.

CASTRO, T. F. e GOLDSCHMIDT, A. I. Aulas práticas em Ciências: concepções de estagiários em licenciatura em biologia e a realidade durante os estágios. Amazônia Revista de Educação em Ciências e Matemática. v.12 (24) Jan-Jul 2016. p. 116-134.

CASTRO, V. M. A et al. Parâmetros microbiológicos de águas de rios coletadas em alguns municípios da Paraíba. Centro de Tecnologia. Departamento de Tecnologia Química e de Alimentos. Monitoria,2003.

CHAGURI, J. P. O uso de atividades lúdicas no processo de ensino/aprendizagem de espanhol como língua estrangeira para aprendizes brasileiros [Internet]. São Paulo: Unicamp; 2006. Disponível em: <http://www.unicamp.br/iel/site/alunos/publicacoes > Acesso em: 26 agosto 2018.

COSTA NETO, E. M. e CARVALHO, P. D. Percepção dos insetos pelos graduandos da Universidade Estadual de Feira de Santana, Bahia, Brasil. Acta Scientiarum, 22 (2): 423$428,2000$.

FORTUNA, T. R. (2003). Sala de aula é lugar de brincar? In: Xavier, M. L. M. \& Zen, M. I. H. D. (Orgs.). Planejamento em destaque: análises menos convencionais (pp. 127-142). 3. ed. Porto Alegre: Mediação

FRACALANZA, H.; AMARAL, I. A. e GOUVEIA, M. S. F. O ensino de Ciências no Primeiro Grau. São Paulo: Atual, 1987. 124 p.

FRANCO, M. T. et al. Aprendizagem em museus de Ciências: o pequeno visitante no Museu de Microbiologia. Relatório de Pesquisa, Fapesp, 2012.

GUIMARÃES, Y. e A. F.; GIORDAN, M. Estudo Dirigido de Iniciação à Sequência Didática. Especialização em Ensino de Ciências, Rede São Paulo de Formação Docente (REDEFOR). Faculdade de Educação da Universidade de São Paulo, 2012.

KLEINKE, R. C. M. Aprendizagem Significativa: a pedagogia por projetos no processo de alfabetização. Florianópolis: UFSC, 2003. Dissertação (Mestrado em Engenharia de Produção). Programa de Pós-Graduação em Engenharia de Produção, Universidade Federal de Santa Catarina, 2003.

KRASILCHIK, M. Prática de Ensino de Biologia. São Paulo: Universidade de São Paulo, $4^{\text {a }}$ ed. 2011.

LEITE, L.; ESTEVES, E. Análise crítica de actividades laboratoriais: Um estudo envolvendo estudantes de graduação. Revista Electrónica de Enseñanza de las Ciencias. v. 4, nº 1. Braga, Portugal: 2005.

LEPORO, N. Micróbios na Educação Infantil: o que as crianças pensam sobre os microrganismos? In: VII Encontro Nacional de Pesquisa em Educação em Ciências, 7, 2009, Florianópolis. Anais do VII ENPEC. Florianópolis: FaE UFMG, 2009.

LOPES, L. A. et al. O uso de tablets como ferramenta para verificar as concepções sobre insetos construídas por estudantes do $7^{\circ}$ ano do Ensino Fundamental. Anais.... In: X Encontro 
Nacional de Pesquisa em Educação em Ciências - X ENPEC. Águas de Lindóia, SP - 24 a 27 de nov. de 2015.

MADIGAN, M.T.; MARTINKO, J.M. e PARKER, J. Microbiologia de Brock. 10. ed. São Paulo: Prentice Hall, 2004. 608p.

MATOS, C. H. C. et al. Utilização de modelos didáticos no ensino de entomologia. Revista de Biologia e Ciências da Terra, Sergipe, v. 9, n. 1, p. 19-23, jan./jun. 2009.

BORGES, C. J. e NEVES, L. O. O Lúdico nas Interfaces das Relações Educativas. Revista de Pedagogia, v. 6, n 12, 2005

NUNES, A. R. S. C. de A. O lúdico na aquisição da segunda língua. Uniandrade: Curitiba. Língua Estrangeira Pro Br, 2003.

PELCZAR, M. J.; CHAN, E. C. S. e KRIEG, N. R. Microbiologia: conceitos e aplicações. 2.ed. São Paulo: Pearson Makron Books, 1997. 524p.

PELIZZARI, A. et al. Teoria da aprendizagem significativa segundo Ausubel. Revista PEC. v.2, n.1, p.37-42, Curitiba: 2002.

PESSOA, T. M. S. C. et al. Percepção dos alunos do Ensino Fundamental da rede pública de Aracaju sobre a relação da Microbiologia no cotidiano. Scientia Plena. vol. 8, num. 4. 2012

PINHO, J. A. Regras da Transposição Didática aplicada ao Laboratório Didático. Caderno Catarinense de Ensino de Física. v. 17, nº 2, p. 174-188. Florianópolis: 2000.

POSSOBOM, C. C. F.; OKADA, F. K. e DINIZ, R. E. S. Atividades práticas de laboratório no ensino de biologia e de Ciências: Relato de uma experiência. In: GARCIA, W. G.;

GUEDES, A. M. (Org.). Núcleos de Ensino - Unesp. 1 ed., v. 1, p. 113-123. São Paulo: 2003.

RIZZO PINTO, J. Corpo, movimento e educação - o desafio da criança e adolescente deficientes sociais. Rio de Janeiro: Sprint, 1997.

SANTOS, S. M. P. dos. (Org.) Brinquedoteca: O Lúdico em diferentes contextos. Petrópolis: Vozes, 1997.

SILVA, D. R. M.; VIEIRA, N. P. e OLIVEIRA, A. M. O ensino de biologia com aulas práticas de microscopia: uma experiência na rede estadual de Sanclerlândia - GO. Anais.... In: III EDIPE - Encontro Estadual de Didática e Prática de Ensino. p. 1-4, 2009.

WELKER, C. A. D. O estudo de bactérias e protistas no ensino médio: uma abordagem menos convencional. Experiências em Ensino de Ciências. v. 2, no 2, p. 69-75. Porto Alegre: 2007.

Recebido em: 08 de agosto de 2018.

Aprovado em: 8 de novembro de 2018. 